\title{
Three-dimensional visualization software assists learning in students with diverse spatial intelligence in medical education
}

\author{
Zehra Jamil \\ Aga Khan University, zehra.jamil@aku.edu \\ Amna A. Saeed \\ Aga Khan University \\ Sarosh Madhani \\ Aga Khan University, sarosh.madhani@aku.edu \\ Safia Baig \\ Aga Khan University \\ Zahra Cheema \\ Aga Khan University
}

See next page for additional authors

Follow this and additional works at: https://ecommons.aku.edu/pakistan_fhs_mc_bbs

Part of the Anatomy Commons, Life Sciences Commons, Medical Education Commons, and the Medical Sciences Commons

\section{Recommended Citation}

Jamil, Z., Saeed, A. A., Madhani, S., Baig, S., Cheema, Z., Fatima, S. S. (2019). Three-dimensional visualization software assists learning in students with diverse spatial intelligence in medical education. Anatomical Sciences Education, 12(5), 550-560.

Available at: https://ecommons.aku.edu/pakistan_fhs_mc_bbs/783 


\section{Authors}

Zehra Jamil, Amna A. Saeed, Sarosh Madhani, Safia Baig, Zahra Cheema, and Syeda Sadia Fatima 
Required software to e-Annotate PDFs: Adobe Acrobat Professional or Adobe Reader (version 11 or above). (Note that this document uses screenshots from Adobe Reader DC.)

The latest version of Acrobat Reader can be downloaded for free at: http://get.adobe.com/reader/

Once you have Acrobat Reader open on your computer, click on the Comment tab (right-hand panel or under the Tools menu).

This will open up a ribbon panel at the top of the document. Using a tool will place a comment in the right-hand panel. The tools you will use for annotating your proof are shown below:

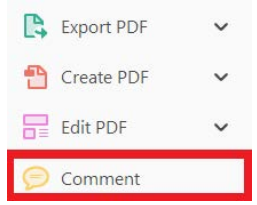

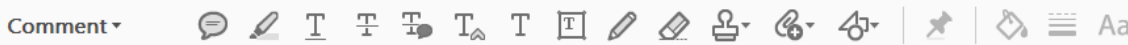

1. Replace (Ins) Tool - for replacing text.

T. Strikes a line through text and opens up a text box where replacement text can be entered.

How to use it:

- Highlight a word or sentence.

- Click on $T_{D}$.

- Type the replacement text into the blue box that appears.

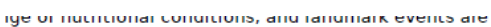
nitored in populations of relatively homogeneous single $\mathrm{n}$ of

and Is initiated atter

carbon source [ 1]. S

are referred to as mei

rof meiosis-specific

inducer of meiosis) [3

I

1 functions as a repre

repression, the genes

pression) and RGRI a।

rase II mediator subur

irectly or indirectly re

Post

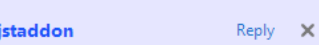

Reply $\times$

$-$

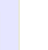


5. Attach File Tool - for inserting large amounts of text or replacement figures.

Inserts an icon linking to the attached file in the Q appropriate place in the text.

How to use it:

- Click on $\&^{\text {- }}$

- Click on the proof to where you'd like the attached file to be linked.

- Select the file to be attached from your computer or network.

- Select the colour and type of icon that will appear in the proof. Click OK.

The attachment appears in the right-hand panel.

:hondrial nreparatior ative da ie extent of membra I, malondialdehyde ( (TBARS) formation.' inad bu biak marfam
6. Add stamp Tool - for approving a proof if no corrections are required.

$\Omega$ Inserts a selected stamp onto an appropriate place in the proof.

How to use it:

- Click on $\Omega$.

- Select the stamp you want to use. (The Approved stamp is usually available directly in the menu that appears. Others are shown under Dynamic, Sign Here, Standard Business).

- Fill in any details and then click on the proof where you'd like the stamp to appear. (Where a proof is to be approved as it is, this would normally be on the first page).

)t the Dusiness cycie, starting with the on perfect competition, constant ret

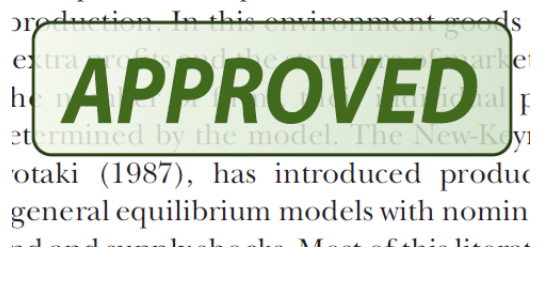

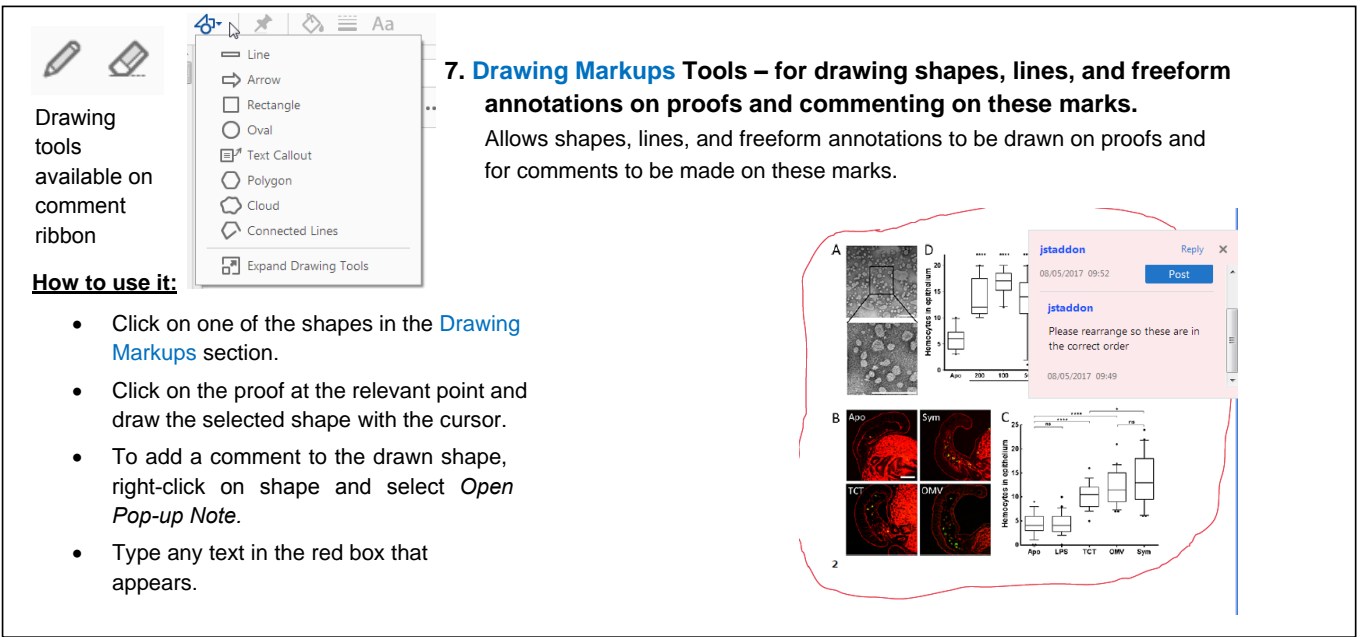

For further information on how to annotate proofs, click on the Help menu to reveal a list of further options:

Welcome...

?) Learn Adobe Acrobat Reader DC..

About Adobe Acrobat Reader DC...

About Adobe Plug-Ins...

Generate System Report...

Repair Installation

Check for Updates... 


\section{Author Query Form}

Journal: ASE

Article: 1828

Dear Author,

During the copyediting of your manuscript, the following queries arose.

Please refer to the query reference callout numbers in the page proofs and respond to each by marking the necessary comments using the PDF annotation tools.

Please remember illegible or unclear comments and corrections may delay publication.

Many thanks for your assistance.

AUTHOR: Please note that missing content in references have been updated where we have been able to match the missing elements without ambiguity against a standard citation database, to meet the reference style requirements of the journal. It is your responsibility to check and ensure that all listed references are complete and accurate.

\begin{tabular}{|l|l|l|}
\hline $\begin{array}{l}\text { Query } \\
\text { reference }\end{array}$ & Query & Remarks \\
\hline 1 & $\begin{array}{l}\text { AUTHOR: Please confirm that given names (blue) and surnames/family names } \\
\text { (vermilion) have been identified correctly. }\end{array}$ & Correction needed \\
\hline 2 & $\begin{array}{l}\text { AUTHOR: Urbaniak and Plous (2018) has not been included in the Reference List, } \\
\text { please supply full publication details. }\end{array}$ & $\begin{array}{l}\text { Citation is } \\
\text { added at pg } 6\end{array}$ \\
\hline 3 & $\begin{array}{l}\text { AUTHOR: Lim et al. (2015) has been changed to Lim et al. (2016) so that this } \\
\text { citation matches the Reference List. Please confirm that this is correct. }\end{array}$ & This is correct \\
\hline
\end{tabular}




\title{
Three-dimensional Visualization Software Assists Learning in Students with Diverse Spatial Intelligence in Medical Education
}

\author{
Zehra Jamil,, ${ }^{1}$ Amna A. Saeed, ${ }^{2}$ Sarosh Madhani, ${ }^{2}$ Safia Baig, ${ }^{2}$ Zahra Cheema, ${ }^{2}$ Syeda S. Fatima (iD) ${ }^{1 *}$ \\ ${ }^{1}$ Department of Biological and Biomedical Sciences, Aedical Coltege, The Aga Khan University, Karachi, Pakistan \\ ${ }^{2}$ Medical College, The Aga Khan University, Karachi, Pakistan
}

This study evaluated effect of mental rotation (MR) training on learning outcomes and explored effectiveness of teaching via three-dimensional (3D) software among medical students with diverse spatial intelligence. Data from $n=67$ student volunteers were included. A preliminary test was conducted to obtain baseline level of MR competency and was utilized to assign participants to two experimental conditions, i.e., trained group $(n=25)$ and untrained group $(n=42)$. Data on the effectiveness of training were collected to measure participants' speed and accuracy in performing various MR activities. Six weeks later, a large class format (LCF) session was conducted for all students using 3D software. The usefulness of technology-assisted learning at the LCF was evaluated via a pre- and post-test. Students' feedback regarding MR training and use of 3D software was acquired through questionnaires. MR scores of the trainees improved from $25.9 \pm 4.6$ points to $28.1 \pm 4.4(P$ $=0.011$ ) while time taken to complete the tasks reduced from $20.9 \pm 3.9$ to $12.2 \pm 4.4 \mathrm{~min}$ utes. Males scored higher than females in all components $(P=0.016)$. Further, higher preand post-test scores were observed in trained $(9.0 \pm 1.9$ and $12.3 \pm 1.6)$ versus untrained group $(7.8 \pm 1.8 ; 10.8 \pm 1.8)$. Although mixed-design analysis of variance suggested significant difference in their test scores $(P<0.001)$, both groups reported similar trend in improvement by means of 3D software $(P=0.54)$. Ninety-seven percent of students reported technology-assisted learning as an effective means of instruction and found use of 3D software superior to plastic models. Software based on 3D technologies could be adopted as an effective teaching pedagogy to support learning across students with diverse levels of mental rotation abilities. Anat Sci Educ 0: 1-12. (C) 2018 American Association of Anatomists.

Key words: gross anatomy education; medical education; undergraduate education; spatial intelligence; mental rotation test; technology enhanced learning; functional anatomy

\section{INTRODUCTION}

"The theory of Multiple Intelligence fragments the domain of "intelligence" into several modalities such as linguistic, logical,

${ }^{*}$ Correspondence to: Dr. Syeda Sadia Fatima, Department of Biological and Biomedical Sciences, Aga Khan University, Stadium Road, Karachi-74800, Pakistan. E-mail: sadia.fatima@aku.edu

Funding agency:This research was funded by the Scholarship of Teaching and Learning grant, Aga Khan University, Kenya (SOTL-YTSF-3D Mental Rotation Ability-51614).

Additional supporting information can be viewed in the online version of this article.

Received 31 January 2018; Revised 7 August 2018; Accepted 8 August 2018.

C 2018 American Association of Anatomists kinesthetic, spatial, musical, naturalist, interpersonal, and intrapersonal (Sternberg, 2015). Among these, spatial intelligence refers to the ability to analyze an object in three-dimensional (3D) and draw conclusions from limited information (Hegarty, 2010). In day-to-day life, these spatial abilities play an important role in the cognitive skills that are used in a variety of tasks. Broadly speaking, Uttal and colleagues have classified these abilities using a $2 \times 2$ table with reference to combination of two dimensions (2D), i.e., dynamic-static and intrinsic-extrinsic (Uttal et al., 2013). The dynamic dimension measures competence in making transformations on moving stimuli while static dimension assess competences in perceiving stationary objects. Within these, dynamic-intrinsic dimension deals with the alteration of objects that are not visible to us thereby requiring mental transformation. This domain of spatial intelligence is commonly termed as mental rotation (MR) 
ability and has gained momentum in science education over the years, especially in medicine and allied health disciplines (Linn and Hyde, 1989).

The term "mental rotation" was first proposed by Shepard and Metzler (1971). They observed participants' ability to distinguish two blocks with three-dimensional mirror images when rotated in space; the time taken for each response was also monitored. They established that response time was proportional to the angular disparity between the two objects and concluded that the participant employed their ability to mentally rotate objects. What followed this breakthrough revelation was a number of studies into understanding MR ability, the factors that can influence it and how could it be improved. Later, studies demonstrated that this skill could be enhanced by training based on repetitive MR exercises (Parsons, 1987; Kail and Park, 1990; Parsons, 1994). Contrary to this, other studies reported that such exercise did not necessarily improve the process of MR itself as they linked the improvement to memorization of the tasks (Tarr and Pinker, 1989). With this impasse, newer hypotheses were brought up that manual rotation might be linked to MR itself. To date, studies employing neurophysiological and neuroimaging have provided evidence that motor and premotor areas of the brain are activated during both execution of movement as well as mental rotation; suggesting that manual rotation training would improve MR skills (Tomasino and Gremese, 2016).

The significance of spatial thinking has already been recognized in successful learning of science, technology, engineering, and mathematics (STEM). Literature suggests that students' spatial skills can be improved through practice, language, gesture, mapping, sketching diagrams, and appropriate use of 3D multimedia software (Newcombe, 2010). Within the realms of medical education, medical professionals often rely on MR ability while performing medical procedures such as clinical examination or surgery, as the internal structures of the body cannot be directly visualized (Petersson et al., 2009). Furthermore, spatial cognition and MR are essential for making sense of radiological images that are two-dimensional (2D) slices of three-dimensional (3D) objects (Vuchkova et al., 2011). Therefore, medical and allied health professionals frequently rely on spatial reasoning during their practice. In the context of anatomy, the study of the human body is particularly linked with the spatial abilities of the medical students (Khalil et al., 2005). A study by Parsons (1994) and more recently by Petit et al. (2003) report that production of a mental image of a body segment requires more time even with no anatomical constraints. What makes MR an important skill is the constant requirement of students to rotate anatomical structures in different planes so to analyze relations between body structures such as muscles, bones, organs, and vasculature (Cui et al., 2016). These results have been reproduced by other researches that report MR as a tool that assisted students while learning anatomy in different visual planes (Cona et al., 2017; Jang et al., 2017). Literature confirms that MR training improves students' performance on anatomy questions requiring spatial abilities (Garg et al., 2001). Furthermore, students lacking MR ability, rely on memorization of multiple views independent of each other that may reduce their efficiency of learning (Hoyek et al., 2009).

In line with the global adoption of organ-based teaching in pre-clerkship medical education, the majority of the medical curricula across Pakistan have transformed into the modular systems integrating the basic science discipline. However, adoption of problem-based learning (PBL) into these modules has led to time constrains for the delivery of the content of anatomy (Memon, 2009). The dearth of literature from our region has led to a lack of evidence to support best practices in the global south contextual setting (Shahab et al., 2016). Currently, at the Aga Khan University, the anatomy curriculum has been arranged across seven modules in the first year and six modules in the second year during the five years of undergraduate medical education. These details have been summarized in Table 1. Overall, the content is delivered through concept-based lectures, small group tutorials, dissection demonstrations and microscopy laboratories. Resources for teaching gross anatomy presently includes plastic models, formalin preserved cadaveric specimens, prosection, and plastinated body specimens. Although there is enough evidence to support the role of cadaveric dissection due to religious, social, and cultural constraints, cadaveric dissection is declining in the current setting (Khan et al., 2014). Moreover there is no legal framework in countries like Pakistan to obtain consented cadaveric material for educational purposes. In such a scenario, computational technologies and plastinated specimens are being procured to provide ample exposure of 3D structural knowledge to the medical students. In respect to students' evaluation, their learning is assessed throughout the year via multiple choice questions (MCQs), short essay questions (SAQs), and computer-based assessment at the end of each module. These computer-based assessments have recently replaced the traditional "Objective Structured Practice Examination" (OSPE). Additionally, end of the year examination includes an "Objective Structured Clinical Examination" (OSCE) with designated stations for anatomical skills, in addition to the MCQs, SAQs and a final viva voce (oral) examination.

To overcome the lack of cadaveric dissection (Memon, 2009; Petersson et al., 2009) and to support the learning of anatomy, computational technologies such as $3 \mathrm{D}$ visualization software are being adopted as they present internal organs in a manner those students may clearly visualize their salient features while orienting them as per their needs. This leads to grasping of the holistic concept of its organization, function as well as placement within the body (Rehman et al., 2012; Cui et al., 2017). Although, the use of 3D visualization software has shown improved students' performance, there are conflicting reports to support their role in assisting students with different levels of MR abilities. In fact, studies have even suggested that presenting information in multiple orientations as with the case of $3 \mathrm{D}$ visualization software, it may place a heavier load on the individual's ability to rotate the structure acutely especially for those with relatively poorer spatial ability (Garg et al., 2002). Therefore, this study aimed to explore the efficacy of mental rotation training on the learning activities of undergraduate medical students. In addition, it assessed the effectiveness of teaching functional anatomy via $3 \mathrm{D}$ visualization software. It was hypothesized that while learning with the assistance of 3D visualization software, students with diverse mental rotation abilities may equally benefit.

\section{MATERIAL AND METHODS}

\section{Study Design and Student Recruitment}

This experimental study was designed to assess the impact of teaching via 3D visualization software in first year undergraduate medical students. In addition, MR training was provided as an intervention to the cases. The study was conducted at the Aga Khan University, Karachi Campus during 2016. 
Summary of the anatomy teaching hours during first and second year of undergraduate medical education at Aga Khan University

\begin{tabular}{|c|c|c|c|c|c|c|c|c|}
\hline Modules & $\begin{array}{l}\text { Duration } \\
\text { (weeks) }\end{array}$ & $\begin{array}{l}\text { Large } \\
\text { Class } \\
\text { Format } \\
\text { (hours) }\end{array}$ & $\begin{array}{l}\text { Embryology } \\
\text { (hours) }\end{array}$ & $\begin{array}{l}\text { Problem } \\
\text { Based } \\
\text { Learning } \\
\text { (hours) }\end{array}$ & $\begin{array}{l}\text { Microscopy } \\
\text { (hours) }\end{array}$ & $\begin{array}{l}\text { Dissection } \\
\text { (hours) }^{a}\end{array}$ & $\begin{array}{l}\text { Tutorial } \\
\text { (hours) }\end{array}$ & $\begin{array}{l}\text { Total } \\
\text { (hours) }\end{array}$ \\
\hline \multicolumn{9}{|l|}{ First year } \\
\hline Introductory & 4 & 1.5 & 2.5 & 10 & 2 & - & - & 20 \\
\hline $\begin{array}{l}\text { Inflammation and } \\
\text { neoplasia }\end{array}$ & 4 & - & 3 & 14.5 & 2.5 & - & - & 24 \\
\hline $\begin{array}{l}\text { GIT, nutrition and } \\
\text { metabolism }\end{array}$ & 6 & 6.5 & 2.5 & 21.5 & 9.5 & 3.5 & 2 & 51.5 \\
\hline Multisystem I & 3 & 1.5 & - & 12 & - & - & - & 16.5 \\
\hline \multicolumn{9}{|l|}{ Second year } \\
\hline Musculoskeletal & 6 & 12.5 & 1.5 & 21.5 & 2 & 24 & 4.5 & 72 \\
\hline Neurosciences & 8 & 15 & 2 & 24 & - & 7 & 4 & 60 \\
\hline Head and neck & 5 & 6 & 1.5 & 19 & 2 & 15.5 & - & 49 \\
\hline $\begin{array}{l}\text { Endocrine and } \\
\text { reproduction }\end{array}$ & 6 & 4 & 2.5 & 23.5 & 13 & 4.5 & - & 53.5 \\
\hline
\end{tabular}

${ }^{\text {a }}$ For these dissection sessions, the class was divided onto two groups and each session was conducted twice: GIT, gastrointestinal tract.

After approval from the institutional Ethical Review Board (4021-BBS-ERC-16), The Aga Khan Medical College offers a five-year Bachelor of Medicine, Bachelor of Surgery (MBBS) program. Admission to the program is based on individual merit and leadership potential, with no discrimination for gender, religion, or ethnicity. Candidates with a minimum score of $60 \%$ in Higher Secondary Science Certificate (HSSC) and/or a minimum of B grade in advanced-level (A-level) biology, physics, and chemistry in the British education system are eligible to apply online from across the globe. A total of 100 students are selected on the bases of a written test, interview, record of a co-curricular and extracurricular activities, and reference letters. A deliberate attempt is made to select students from diverse educational and economic backgrounds. Financial assistance is also available for motivated students. The study cohort comprised of $n=71$ students 15 of them having an HSSC background while 56 with A-level qualifications. A written and informed consent was sought from all the participants. All enrolled students were given a preliminary test in order to obtain the baseline level of MR competency using Vandenberg and Kuse Mental Rotations Test (Vandenberg and Kuse, 1978). Then, the study participants were randomly divided into two experimental groups by using Research Randomizer software (Urbaniak and Plous, 2018). Students selected for MR Training were labeled as "Cases" $(\mathrm{n}=35)$ and received the intervention i.e., a short training while the untrained group was labeled as "Controls" ( $\mathrm{n}=36$ ) and did not receive any such training. Both the groups were homogenized on basis of age, gender, and baseline MR competency test results, therefore comprised of an equal proportion of males and females as well as those with high and low MR ability.

At the Aga Khan University, first-year undergraduate medical education comprises of seven modules (Table 1). The whole class is simultaneously taken through the same modules at one point in time. By the time they reach the last module, they have covered the major organ systems that are part of their curriculum. The multisystem module is placed at the end of the year and consists of overarching concepts that impacts more than one system such as septicemia, genetic syndromes, autoimmune disorders, etc. 


\section{Mental Rotation Training Workshop}

A day-long MR training workshop was conducted for the selected students (Cases), on August 13, 2016. On the day of MR training workshop, 29 out of 35 students showed up and were trained accordingly. However, 4 of these trained students later dropped out of the study due to personal reasons. As a result, data of 25 students were included as part of the "trained" group that received intervention. In order to assess the baseline levels of the participants, a pretest was conducted at the beginning of this session, which comprised of two sections; generic section and medical domain-specific section. The scores as well as the time taken to complete these tasks were monitored separately for both the genders. Next, they were briefly introduced to the concept of multiple intelligence including spatial skills. The usefulness of the MR ability was explained with the evidence of its role in STEM education.

For the generic section of training, participants were engaged in diverse activities included online games (Labranche et al., 2014) offered by free websites such as Tetris (2018), SharpBrains (2010), and Cambridge Brain Science (2018). As the literature suggest that MR training is domain specific (National Research Council, 2006), additional activities were incorporated based on rotation of human body, its organs and tissues in various directions. Tasks were specifically designed for the student to apply their MR abilities in order to experience in-depth orientation of the body structures. Brief scenarios were provided to the trainees that encouraged them to imagine specific organs in a certain position. This was followed by the hands-on practice

\section{Which option is marked with one right and one left hand}

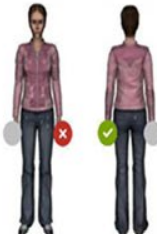

A

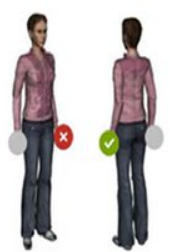

B

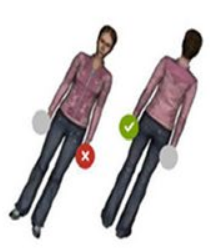

C

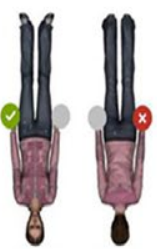

D

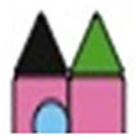

2. Which of the three images corresponds to the house shown above

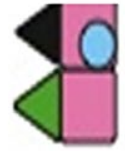

A

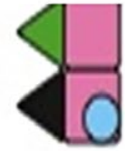

B

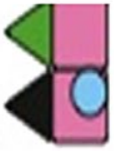

C

\section{Suppose an image of the heart is captured from behind, as shown in the figure this image. Choose the best option that represents to positioning of heart in this case.}

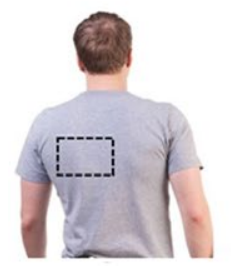

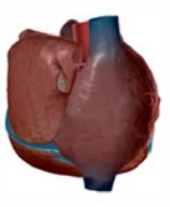

A

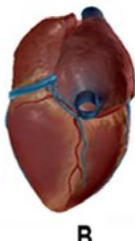

B

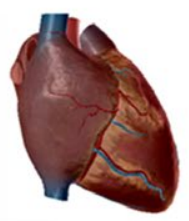

C

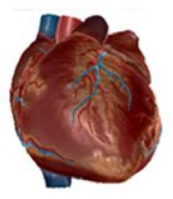

D

\section{Figure 1.}

Sample of multiple choice questions used during the training workshop. 
using 3D software to visualize the internal structures. The aim of this training was to establish a platform where participants learn to mentally rotate an organ and predict its structure when viewed from different planes and dimensions. Sample questions from both the sections have been shared in Figure 1.

The workshop was conducted by the investigators along with research associates. At the end of this workshop, the same questionnaire comprising of MCQs was offered as a post-test to obtain the practice effect of the intervention on the level of MR competency. The Kendalls tau B test was applied on the knowledge test administered to the study participants. The Kendalls tau B score was 0.79 that depicted a strong correlation and validity.

Students' feedback regarding this session was sought via questionnaire based on a Likert scale. Their preference for strategies to mentally rotate an object was also collected via a form adopted from the literature after seeking permission from the author (Peters et al., 1995).

The untrained group served as controls as they were not invited to the workshop in August, 2016. Once data were collected from them as controls, this group received a similar delayed intervention (MR workshop) at the end of the study project (November, 2016) in order to maintain equal opportunity for all the students to avail from MR training as an ethical practice.

\section{Teaching Session}

Six weeks after the workshop, a large class format (LCF) teaching session was organized spanning two hours during the Multisystem-I module. This session was conducted jointly for both the groups', i.e., MR trained and untrained. On the day of the lecture, controls $(n=36)$ were joined by an additional 6 students, finally constituting a cohort of $n=42$ students in the "untrained/control" group. Sixty-seven students in total attended this session (25 trained and 42 untrained) where MCQ-based pre-test was conducted to analyze the utility of MR training by comparison of the scores of trained and untrained group. During this session, clinical scenarios based on concepts of functional anatomy pertaining to gastro-intestinal tract, cardiovascular, respiratory, and renal system were taught via 3D visualization software titled Human Anatomy Atlas from Visible Body (2018). A post-test was conducted to assess the gain of knowledge while studying via $3 \mathrm{D}$ visualization software (example questions are provided in supplementary materials). Difficulty index was calculated for the test with a mean score of 71.23. A majority of the questions were C2 level according to the Blooms taxonomy.

The response rate for the questionnaire administered to assess students' perception regarding the workshop as well as the lecture was $100 \%$ for the cohort. A reliability analysis was carried out on the perceived task values scale comprising 10 items for the lecture and 6 items for the training workshop. Cronbach's alpha showed the questionnaire to reach acceptable reliability, $\alpha=0.811$ and $\alpha=0.814$, respectively. All items appeared to be worthy of retention, resulting in a decrease in the alpha if deleted.

A schematic flow of events in the experiment is depicted as Figure 2.

\section{Statistical Analysis}

Data were stored and analyzed using the SPSS statistical package, version 21.0. (IBM Corp. Armonk, NY). Means with standard deviation were reported for the time taken in test and total scores. In order to compare the effect workshop, paired sample t-test was applied on the scores of pre- and post-tests. Furthermore, to compare the effect of learning from 3D software in the lecture, independent sample t-test was applied. The data collected from the lecture were also investigated using multivariate generalized linear model (Split plot ANOVA) to compare the effect of learning on the MR trained and untrained group. Kendall's tau B and Cronbach's alpha were calculated. The effect size for performance of the cohorts with and without training was calculated by Cohen's $d$ test. Students' feedback was reported as frequencies. Bar chart and mean plots were used to display the means of the parameters. In all instances, $P$-values less than 0.05 was considered as significant.

\section{RESULTS}

Although, 71 students gave a written consent to participate in the study, data of 67 students have been included in this analysis who participated from the beginning until the end. The mean age of the study participants was $18.85 \pm 2.02$ years. Out of $\mathrm{n}=25 \mathrm{MR}$ trained participants, 11 male and 14 female comprised the Case group; whereas out of $n=42$ controls, 22 where male and 20 females.

\section{Analysis of the Mental Rotation training workshop}

Table 2 presents the mean scores of participants attending the MR training workshop. A significant increase $(P=0.017)$ in the performance of the trainees was observed as their mean scores improved from $25.56 \pm 4.37$ to $27.92 \pm 4.35$ (from $73.02 \%$ to $79.77 \%$ ). Likewise, the total time taken to complete these tasks was reduced from $20.9 \pm 3.9$ minutes to 12.2 \pm 4.4 minutes $(P<0.001)$. Male participants scored higher than females in all the components of MR training $(P=0.016)$ (Table 3).

The students' feedback regarding usefulness of MR training workshop has been summarized in Figure 3. They strongly recommended the incorporation of $3 \mathrm{D}$ visualization software as part of curriculum delivery. Regarding the preferences of the workshop participants, the majority of them reported use of multimodal strategies while mentally rotating an object. These responses are summarized in a supplementary table.

\section{Analysis of the Teaching Session (large Class Format) with Incorporation of 3D Visualization Software}

In the teaching session, the impact of learning via 3D software was analyzed by paired t test as summarized in Table 4 . A substantial improvement was noticed in the performance of both the groups as indicated by an improvement in the post-test scores. The trained group scored $82.3 \%$ in the post-test which was significantly higher than their pre-test scores of $60.0 \%$. Likewise, post-test scores of the untrained group significantly improved to $70.2 \%$ from their pre-test scores of $52.0 \%$.

Next, two-independent sample $t$ test was applied to analyze the differences in the lecture scores of the MR trained and untrained group. In the pre-test trained group scored higher than the untrained group $(P<0.001)$, similarly the post-test performance of the trained group was also observed to be 


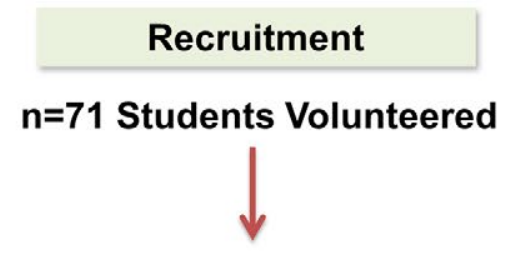

Written and Informed Consent<smiles>C[Al]1CC1</smiles>

Preliminary Test for Baseline Mental Rotation Score<smiles>C[Al]1CC1</smiles>

\section{Random Distribution}

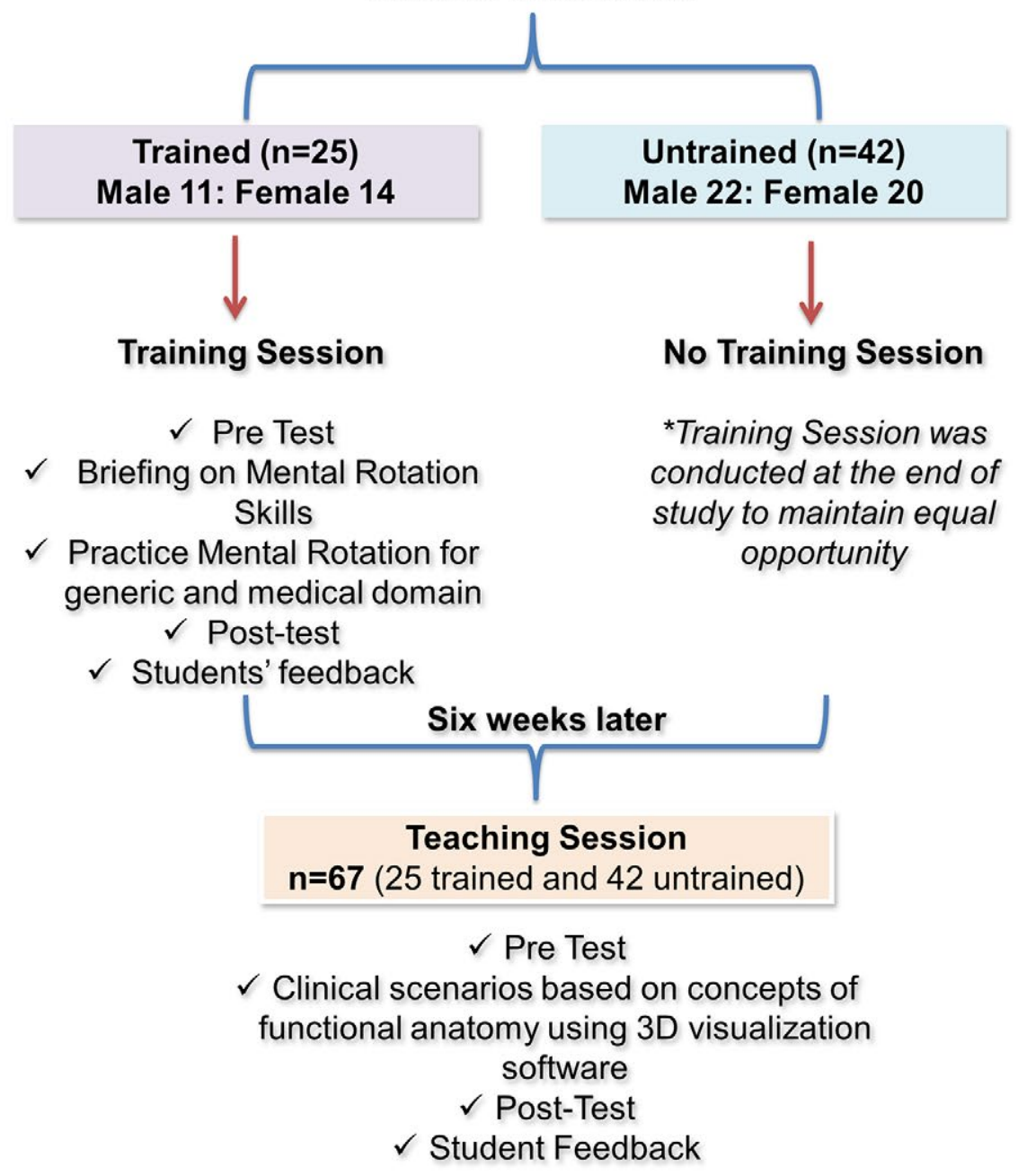

Figure 2.

Schematic representation of flow of events from recruitment through training.

significantly higher than the untrained group $(P<0.001)$. The effect size using Cohen's $d$ measure between the untrained and trained group was obtained as 1.57 and 1.33 by, respectively.

In order to further evaluate the usefulness of $3 \mathrm{D}$ software application and have a better insight of the learning,
Mixed-design (split-plot) analysis of variance (ANOVA) was applied to compare the impact on knowledge gained within each group. The analyses suggested that although there was a significant difference in the pre- and post-test scores of the two groups, both groups reported similar trends in overall improvement 
Table 2.

Comparison of Mean Scores of participants attending the mental rotation (MR) training workshop

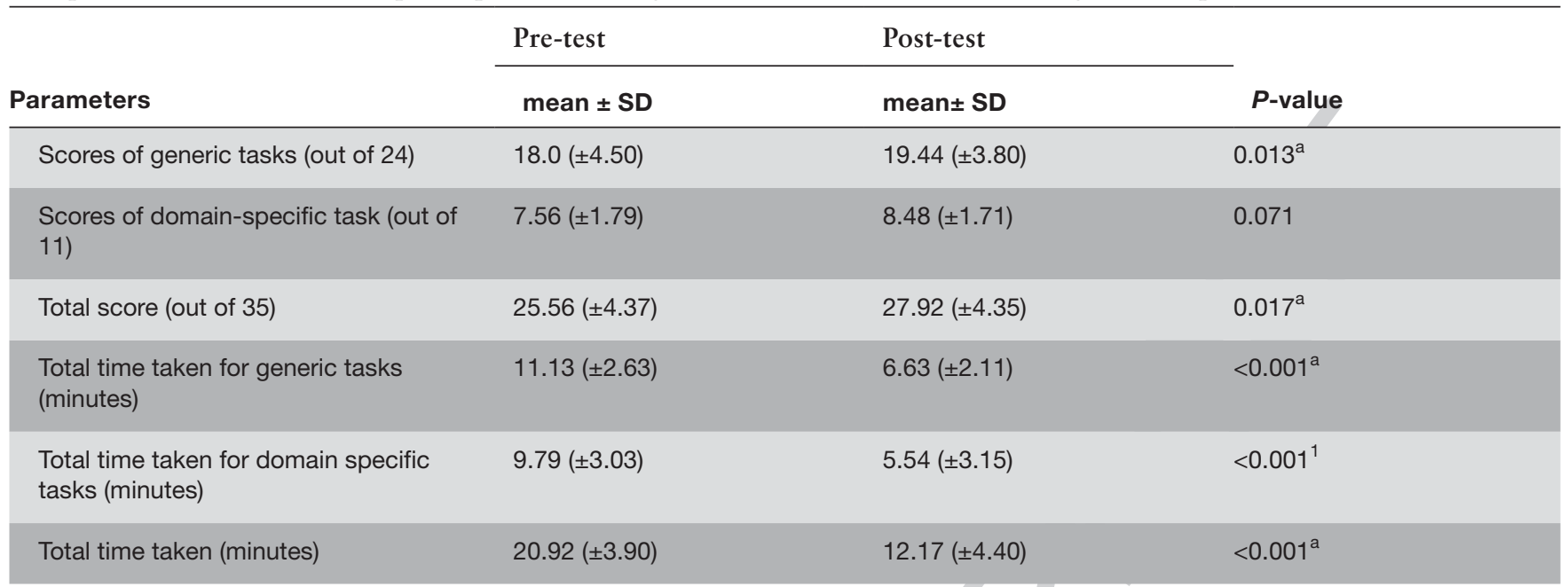

${ }^{\text {a }} P$-value obtained using paired sample t-test; number of participants $(\mathrm{n}=25)$.

\section{Table 3.}

Comparison of free online game scores of Tetris and mental rotation test between the genders

\begin{tabular}{|c|c|c|c|c|}
\hline Tetris & Males & 12 & $4186.70( \pm 6235.80)$ & $0.0025^{a}$ \\
\hline $\begin{array}{l}\text { Cambridge Brain Science } \\
\text { rotation task }\end{array}$ & Males & 12 & $52.40( \pm 48.34)$ & 0.79 \\
\hline
\end{tabular}

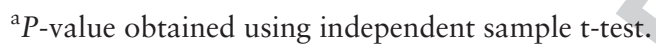

\section{Statement}

Enhanced ability to imagine internal structures that are...

Better mode of teaching and learning than plastic models Should be incorporated as part of the curriculum delivery Ability to mentally rotate objects was up-skilled Mental rotation training helped in learning Ability to assimilate knowledge about 3D mental rotation

$\begin{array}{lcccc}\begin{array}{c}1 \\ \text { Strongly } \\ \text { disagree }\end{array} & 2 & 3 & 4 & 5 \\ \text { Likert Scale } & & \begin{array}{c}\text { Strongly } \\ \text { agree }\end{array}\end{array}$

\section{Figure 3.}

Feedback of the students regarding usefulness of mental rotation $(M R)$ training workshop $(n=25)$. Data presented as mean and standard deviation for each item on the questionnaire. Students scored each question based on a five-point Likert scale where $1=$ strongly disagree and $5=$ strongly agree. 
Measuring the effect of mental rotation training on pre- and post-test scores of the lecture session delivered with assistance of 3D software

\begin{tabular}{llccc}
\hline Variable & Parameter & Test Score \% $( \pm$ SD $)$ & P-value & Effect Size Cohen's $\boldsymbol{d}$ \\
\hline Untrained group $(\mathrm{n}=42)$ & Pre-test & $52.0( \pm 6.6)$ & $0.005^{\mathrm{a}}$ & 1.57 \\
& Post-test & $70.2( \pm 7.9)$ & & \\
& Pre-test & $60.0( \pm 5.1)$ & $0.002^{\mathrm{a}}$ & 1.33
\end{tabular}

${ }^{a} P$-value calculated by paired students t-test, inferring difference between pre-test and post-test performance within each group.

of the scores by means of learning via $3 \mathrm{D}$ software (Fig. 4). The test within-subject effects was not significant $(P=0.373)$, suggesting similar learning effect on trained as well as untrained participants while being taught via 3D software.

The students' feedback regarding usefulness of this software application is presented in Figure 5. A vast majority reported this learning tool as an effective means of instruction, superior to plastic models for visualization of internal structures and worth facilitating retention of the core knowledge of anatomical structures. Thus $89 \%$ students either strongly agreed or agreed for incorporation of technology-assisted learning tools in the curriculum delivery. Selected comments have been summarized below.

- Visualization software gave an opportunity to explore detailed structures from inside out that is the true essence of anatomy learning instead of rote memorization of these relations

80

\section{Estimated Marginal Means of Learning} 100

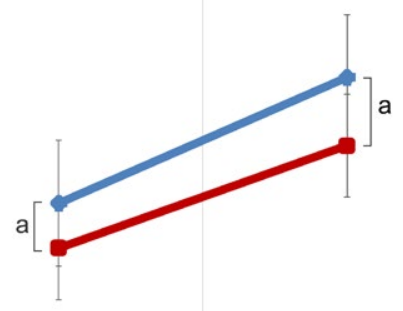

40

0

\section{Study Groups \\ $\approx$ Trained \\ - Untrained}

Pre-test

Post-test

\section{Figure 4.}

Multivariate generalized linear model reporting no difference in the learning outcomes of the students when taught with the assistance of $3 \mathrm{D}$ software application $(P=0.373)$. The blue line (round heads) represents the mental rotation (MR) trained group and the red line (square heads) reports untrained group; ${ }^{\mathrm{a}} \mathrm{P}<0.001$.
- This application should be available to practice during our self-studies so that we may augment the bookish knowledge to visualization of the structures

- I could see even behind and inside the organs but it will take time to grasp the learning from the software as I was lost whenever the positions were hurriedly changed

- This software made anatomy as a whole much more interesting

- It really helped except for the fact that when isolated portions were focused, I got lost. The structures should be labeled each time the frame is changed

- Today, I have retained the knowledge about the arteries and the veins, especially their relations which I could never grasp from lectures or pictures

- It really helped clarify the relationship of different structures in the context of their neighboring organs. Should be added to the current resources for teaching anatomy

- Dissecting layer by layer helped me built a clear concept of the arrangement of the structures. As functional anatomy critically depends on this arrangement, 3D tool greatly helped in this visualization

- I believe that visual memory is more long lasting, hence the software really helped me. However, it should be used for small group teaching to minimize distractions

- This is a more comprehensive way of learning anatomy. Once we have learned the body anatomically, building up further understanding of pathophysiology will become much more practical

\section{DISCUSSION}

This study gathers supporting evidence in favor of educational effectiveness of the $3 \mathrm{D}$ visualization software on anatomy learning during undergraduate medical education. This visualization software adds value to the already existing pedagogies for learning anatomy particularly across students with diverse mental rotation abilities.

In this study, participants selected for MR training workshop broadened their concepts regarding spatial intelligence. This workshop emphasized the role of MR in acquisition of the core knowledge of anatomical sciences. These trainees practiced MR skills using freely available online games and a significant improvement in their performance scores was observed at the end of the training session (Table 3). This is in line with the literature that reports a positive impact of MR training on the prior ability of an individual, however as it is 


\section{Statement}

This activity added enthusiasm towards integrated learning

My learning was stimualted when education is grounded with technology

In depth observation of normal viscera assisted in understanding the structure-function relationship Studying human organs using 3D software was a good alternative to plastic models

I was able to pick up the misconceptions by using 3D visualization

Quiz using 3D images provided me with useful evidence of my understanding

Personally dissecting the organs on 3D software lead to extended retention of the knowledge

Such software might be helpful in revising normal structures during clinical years

It was an overwhelming exersice

This teaching \& learning approach can become an important part of curriculum

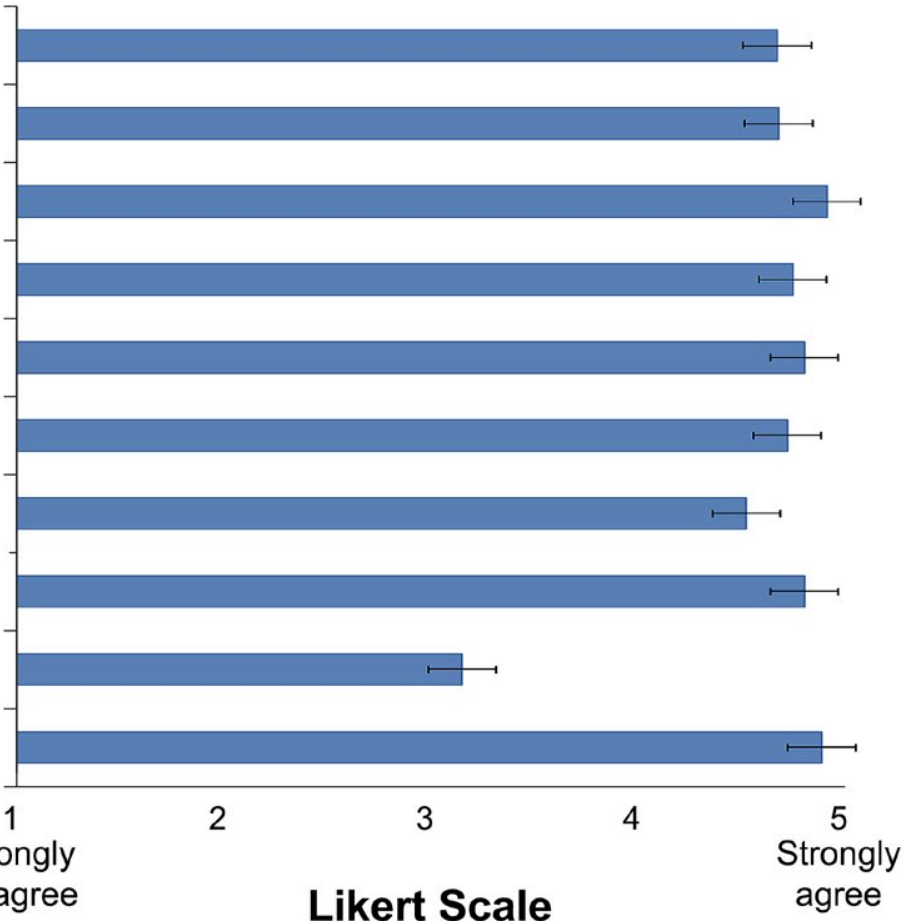

\section{Figure 5.}

Feedback to 3D mental rotation large class format (LCF) student's engagement questionnaire. The responses are shown as bars with standard deviation. Students scored each question based on a five-point Likert scale where $1=$ strongly disagree and $5=$ strongly agree .

domain specific, enhancement is only observed while mentally rotating precise structures (Sims and Mayer, 2002). Therefore, in addition to Tetris and other mental rotation games, the participants practiced rotation of internal body structures, placement in specific positions, and manipulation in particular directions in order to gain exposure of domain-specific MR. They were encouraged to practice their own preferable styles of MR rather than acquiring newer skills to mentally rotate any particular structure. At the end of the training, an improvement was observed in both; the general MR skills as well as medical domain-specific skills (via 3D software) in addition to less time taken to complete the tasks (Table 2). The study participants individually practiced rotation tasks on the software as the literature suggests that direct manipulation of virtual structures facilitates embodiment of the anatomical structure better than passive visualization (Jang et al., 2017). Moreover, Lufler and colleagues reported students' pre-existing visual-spatial ability as a reliable predictor of their performance in medical gross anatomy and further concludes that participation in medical gross anatomy itself does increases students' visual-spatial ability in the long run, though the mechanism behind this phenomenon remain unknown (Lufler et al., 2012). However, Kopp and Rathmell cautiously suggests that instead of utilizing MR assessment for admissions to medical schools, its assessment should be used to identify learners that may benefit from additional practice with different types of learning experiences as they reported the visuo-spatial abilities as a predictor of technical performance of medical students on ultrasound tasks (Kopp and Rathmell, 2015).
Neuroscientists have explored numerous scientific mechanisms behind spatial ability (Tosto et al., 2014). Research on this aspect reveals individual differences in the ability to adaptively choose and use external visual-spatial representations for any task (Hegarty et al., 2007). In line with these studies, the workshop participants reported individual variation in adopting multiple methods while mentally rotating various objects. Thus, it is of utmost importance to acknowledge this diversity in order to avoid demolition of one's natural MR ability while training them to spatially rotate.

The participants of MR training endorsed the gains in their ability to imagine internal structures that could not be directly visualized on the surface of the body. Hence, students who received the training agreed that it enabled better conception of clinical and applied anatomy. Likewise, prior knowledge of MR techniques was stated to augment their ability to utilize the $3 \mathrm{D}$ visualization software. This software was rated better than the anatomical plastic models as the participants' learning was stimulated when grounded with holistic visualization. Literature already supports the significance of improved MR test performance, use of visualization software and their association with anatomy learning which is essential for the training of well informed and competent clinician (Hoyek et al., 2009).

Meta-analysis published on the effect of computer aided instructions in the field of anatomy reports a moderately positive effect on learner performance while measuring short-term knowledge gains as the learning outcome (Wilson et al., 2018). The assistive roles of latest technologies such as computer-assisted software, 3D-printers, mobile pop-up facility, Google 
Glass and augmented reality seems to be a productive elaboration to already existing anatomy teaching pedagogies (Nguyen et al., 2012; Lewis et al., 2014; Trelease, 2016).

Subsequently, this study explored the effectiveness of learning via 3D software application for students with or without MR training. The large class format was conducted at the end of the first year, where functional anatomy of gastro-intestinal, cardiovascular, respiratory and renal system was revisited using anatomy software (Visible Body, 2018). This session was conducted for the students with prior exposure to learning of anatomy via PowerPoint (Microsoft Corp., Redmond, WA) presentations and dissection laboratory sessions utilizing plastic models and cadaveric specimens. The baseline students' knowledge was reflected by the scores of the pretest designed to evaluate anatomical knowledge aspects that required spatial learning. The students with prior MR training scored significantly higher than the untrained group, providing evidence of the impact of MR training. This impact is supported by the evidence particularly for those with lower spatial abilities on the learning science, technology, engineering, and mathematics as well as surgery and anatomy (Roach et al., 2018). In this study, higher learning of students who received prior MR training was evident by their scores, further supporting the existing evidence (McManus et al., 2003). During this interactive LCF, students were engaged to learn via $3 \mathrm{D}$ visualization software for the first time during medical education where they applied the structural knowledge in the context of clinical correlates. Regarding the post-test results of the LCF, in comparison to the untrained group, the MR-trained students scored higher as expected (Table 4). Interestingly, both the groups significantly improved their scores in comparison to their pre-test, supporting the usefulness of teaching via 3D software $(P=0.002$ and $P$ $=0.005)$. It was observed that the trend of gain in the scores was comparable between the MR trained and the untrained group, supported by a non-significant difference in the learning effect $(P=0.373)$. Learning via 3D software application led to similar performance gain among students with or without prior MR training and thus different levels of MR abilities. Berney and colleagues have also shown the impact of using 3D models to support spatial difficulties encountered with traditional static learning; however, they did not assess the baseline MR ability of their students (Berney et al., 2015). The global upward trend of adopting educational technologies both in the preclinical as well as clinical training is evident by the supporting literature as it leads to enhanced learning experience of the students (Han et al., 2013). Resources such as human plastinated specimens, visualization software and simulators are found to improve the preparedness of medical students before they actually examine the real human body in clinical education (McLachlan et al., 2004; Fruhstorfer et al., 2011). This study further adds to the existing literature and provides scientific evidence of the usefulness of augmenting currently available resources with 3D visualization software.

Humans are born with spatial intelligence that exhibit gender variance; males reporting a higher level of MR ability than females (National Research Council, 2006). Likewise during the MR training workshop, the male participants outperformed the females as demonstrated by higher scores and reduced time taken to complete the tasks. However, the use of 3D software during the LCF led to homogenous learning in both the genders as no difference was observed in the test scores of male and female students. These results support the literature highlighting the usefulness of $3 \mathrm{D}$ visualization applications across diverse population (Khot et al., 2013; Lim et al., 2016).
Contrary to these findings, there are conflicting reports 3 on the effectiveness of computer-based educational resources (Khot et al., 2013), as well as the role of MR trainings and spatial intelligence. Sweeney and his group suggested a cautious use of spatial ability to predict teaching of anatomy in their study. He compared a series of tests of spatial ability to the anatomy examination scores in biomedical sciences course and observed weak association (Sweeney et al., 2014). Furthermore, a recent meta-analysis comprehensively discussed a non-significant association of spatial intelligence with MCQs or essay-type assessment; however, it reported strong association with practical examination (Langlois et al., 2017). As the practical component involves synthesis of information from $2 \mathrm{D}$ to $3 \mathrm{D}$ views such as evaluating cross-sections, spatial competencies play an important role while on the other hand; multiple choice or short essay type questions often deal with the non-spatial component of the anatomy learning. This meta-analysis provides a meaningful explanation for the reasons behind the conflict in the literature regarding the relationship between spatial intelligence and functional anatomy as there is strong association with the spatial components of anatomy while non-convincing reports for the concepts that involve non-spatial components. Besides, influence of addition of $3 \mathrm{D}$ and digital teaching tools to a traditional dissection and lecture learning format in a graduate level course of gross and neuro-anatomy has also been documented (Peterson and Mlynarczyk, 2016). This finding endorses the incremental contributions of technology-assisted learning not only in undergraduate curriculum but across the field of anatomical sciences.

Overall, the perception of the study participants regarding the level of visualization via such software in the LCF was encouraging. However, besides the positive impact of the use of 3D technology, approximately $26 \%$ study participants reported that learning via such software was overwhelming for them. As they were experiencing it for the first time, building up concepts while the structures are being constantly manipulated seemed challenging. Although the Generation $\mathrm{Z}$ are assumed to be enormously tech-friendly (Hope, 2018), adoption to technology enhanced learning tools should be a gradual process. This could be either built in small group teaching sessions or could be arranged as self-guided practice. It is essential to recognize that the teaching methodologies are being augmented with these tools; the core aim should be to maximize learning instead of mere addition of technology. Therefore, students should be provided with sufficient time to adapt to newer pedagogies especially before engaging such tools in assessment strategies.

A report published by The National Research Council in 2006 claims that spatial intelligence is not just under-supported but under-appreciated, under-valued, and therefore under-instructed (National Research Council, 2006). Although, medical educators are incorporating numerous technology-assisted learning tools, there is a lack of evidence to support their role in achieving long-term learning outcomes. As the learner of today's world learns differently, adoption of latest teaching tools have become a necessity. These tools allow better visualization of the content and are suggested to profoundly impact one's learning. This study is an effort to highlight the impact of such visualization applications on the learning of students including those with lower MR abilities. This evidence creates an additional support for incorporation of computer-assisted tools to maximize learning outcomes in medical education. 


\section{Limitation of the study}

The limitations of this study include the inability to compare the impact of training and use of 3D software on long-term retention of the knowledge. The summative examination scores of the trained and untrained groups could not be compared due to ethical limitations; hence, these results may not be generalized for the gains of using 3D software on long term retention of the knowledge. Secondly, in addition to mental rotation, spatial skills include multiple domains such as spatial visualization and spatial perception; however this study only assessed the impact of MR training and learning with 3D software on students with different MR abilities. Another limitation is the study population that exclusively comprised of first year students, limiting the findings to only certain group of learner. Further effort is required to expand such experiments across all the levels of medical education in order to gather holistic evidence of its role in not only pre-clerkship years but during clinical clerkship.

\section{CONCLUSION}

Mental rotation domain of the spatial thinking abilities improve through training that can be used to augment anatomy learning. As the latest technologies promote multi-dimensional visualization, software based on $3 \mathrm{D}$ technologies is effective tools in addition to the already existing teaching pedagogies of anatomy learning. As technology-assisted teaching tools will play a pivotal role in the future, professional development of the facilitators to utilize such tools require equivocal consideration.

\section{ACKNOWLEDGMENT}

The authors wish to acknowledge Network of Teaching and Learning, Curriculum committee and Department of Biological and Biomedical Sciences, Aga Khan University for providing us this opportunity to pilot this project. The authors declare that they have no conflict of interest. Part of this work was presented as oral communication in Scholarship of Teaching and Learning (SOTL) in the South conference held in July 2017 at Johannesburg, South Africa.

\section{NOTES ON CONTRIBUTORS}

ZEHRA JAMIL, M.B.B.S., M.Phil. is a senior instructor of anatomy in the Department of Biological and Biomedical Sciences, Aga Khan University, Karachi, Pakistan. She teaches embryology and histology to undergraduate medical students. She has a special interest in educational research in addition to endocrinology and gut microbiome.

AMNA AFZAL SAEED, is a fourth-year M.B.B.S. student at the Aga Khan University Medical College, Karachi, Pakistan. Her field of interest is in pediatrics.

SAROSH MADHANI, is a fifth-year M.B.B.S. student at the Aga Khan University Medical College, Karachi, Pakistan. His field of interest is in neurosurgery.

SAFIA BAIG, is a fifth-year M.B.B.S. student at the Aga Khan University Medical College, Karachi, Pakistan. Her field of interest is in neurosciences.

ZAHRA CHEEMA, is a fifth-year M.B.B.S. student at the Aga Khan University Medical College, Karachi, Pakistan. Her field of interest is in internal medicine.
SYEDA SADIA FATIMA, M.B.B.S., Ph.D., is an assistant professor of physiology in the Department of Biological and Biomedical Sciences, Aga Khan University, Karachi, Pakistan. She teaches medical and nursing students. Her research interests are in medical education and metabolic syndrome.

\section{LITERATURE CITED}

Berney S, Bétrancourt M, Molinari G, Hoyek N. 2015. How spatial abilities and dynamic visualizations interplay when learning functional anatomy with $3 \mathrm{D}$ anatomical models. Anat Sci Educ 8:452-462.

Cambridge Brain Science. 2018. Rotations. Cambridge Brain Sciences, Toronto, Ontario, Canada. URL: https://www.cambridgebrainsciences.com/play/rotation-task [accessed 30 April 2018].

Cona G, Marino G, Semenza C. 2017. TMS of supplementary motor area (SMA) facilitates mental rotation performance: Evidence for sequence processing in SMA. Neuroimage 146:770-777.

Cui D, Wilson TD, Rockhold RW, Lehman MN, Lynch JC. 2016. Stereoscopic (3D) visualization improves medical student comprehension of head and neck vascular anatomy. FASEB J 30:S570.7.

Cui D, Wilson TD, Rockhold RW, Lehman MN, Lynch JC. 2017. Evaluation of the effectiveness of $3 \mathrm{D}$ vascular stereoscopic models in anatomy instruction for first year medical students. Anat Sci Educ 10:34-45.

Fruhstorfer BH, Palmer J, Brydges S, Abrahams PH. 2011 The use of plastinated prosections for teaching anatomy-The view of medical students on the value of this learning resource. Clin Anat 24:246-252.

Garg AX, Norman G, Sperotable L. 2001. How medical students learn spatial anatomy. Lancet 357:363-364.

Garg AX, Norman GR, Eva KW, Spero L, Sharan S. 2002. Is there any real virtue of virtual reality?: The minor role of multiple orientations in learning anatomy from computers. Acad Med 77:S97-S99.

Han H, Resch DS, Kovach RA. 2013. Educational technology in medical education. Teach Learn Med 25:S39-S43.

Hegarty M. 2010. Components of spatial intelligence. Psychol Learn Motiv 52:265-297.

Hegarty M, Keehner M, Cohen C, Montello DR, Lippa Y. 2007. The role of spatial cognition in medicine: Applications for selecting and training professionals. In: Allen GL (Editor). Applied Spatial Cognition from Research to Cognitive Technology. 1st Ed. Mahwah, NJ: Lawrence Erlbaum Associates, Inc. p 285-315.

Hope JK. 2018. Could educational technology replace traditional schools in the future? In: Khosrow-Pour M (Editor). Encyclopedia of Information Science and Technology. 4th Ed. Hershey, PA: IGI Global. p 2421-2430.

Hoyek N, Collet C, Rastello O, Fargier P, Thiriet P, Guillot A. (2009) Enhancement of mental rotations abilities and its effect on anatomy learning. Teach Learn Med 21:201-206.

Jang S, Vitale JM, Jyung RW, Black JB. 2017. Direct manipulation is better than passive viewing for learning anatomy in a three-dimensional virtual reality environment. Comput Educ 106:150-165.

Kail R, Park YS. 1990. Impact of practice on speed of mental rotation. J Exp Child Psychol 49:227-244.

Khalil MK, Paas F, Johnson TE, Payer AF. 2005. Interactive and dynamic visualizations in teaching and learning of anatomy: A cognitive load perspective. Anat Rec 286B:8-14.

Khan AN, Baig S, Zain S. 2014. Importance of cadaveric dissection in learning gross anatomy. Pak J Med Dent 3:31-35.

Khot Z, Quinlan K, Norman GR, Wainman B. 2013. The relative effectiveness of computer-based and traditional resources for education in anatomy. Anat Sci Educ 6:211-215.

Kopp SL, Rathmell JP. 2015. Acquiring new technical skills and aptitude for mental rotation. Anesthesiology 123:993-994.

Labranche L, Johnson M, Allman B, Nguyen N. 2014. Tetris as homework: Does videogame training improve spatial anatomy comprehension? FASEB J 28:S725.4. Langlois J, Bellemare C, Toulouse J, Wells GA. 2017. Spatial abilities and anatomy knowledge assessment: A systematic review. Anat Sci Educ 10:235-141.

Lewis TL, Burnett B, Tunstall RG, Abrahams PH. 2014. Complementing anatomy education using three-dimensional anatomy mobile software applications on tablet computers. Clin Anat 27:313-320.

Lim KH, Loo ZY, Goldie SJ, Adams JW, McMenamin PG. 2016. Use of 3D printed models in medical education: A randomized control trial comparing 3D prints versus cadaveric materials for learning external cardiac anatomy. Anat Sci Educ 9:213-221.

Linn MC, Hyde JS. 1989. Gender, mathematics, and science. Educ Res 18:17-27. Lufler RS, Zumwalt AC, Romney CA, Hoagland TM. 2012. Effect of visual-spatial ability on medical students' performance in a gross anatomy course. Anat Sci Educ 5:3-9.

McLachlan JC, Bligh J, Bradley P, Searle J. 2004. Teaching anatomy without cadavers. Med Educ 38:418-424. 
McManus IC, Smithers E, Partridge P, Keeling A, Fleming PR. 2003. A levels and intelligence as predictors of medical careers in UK doctors: 20 year prospective study. BMJ 327:139-142.

Memon IK. 2009. Anatomy education faces challenges in Pakistan. Anat Sci Educ 2:193-194.

National Research Council. 2006. Learning to Think Spatially: GIS as a Support System in the K-12 Curriculum. 1st Ed. Washington DC: The National Academies Press. 332 p.

Newcombe NS. 2010. Picture this: Increasing math and science learning by improving spatial thinking. Am Educ 34:29.

Nguyen N, Nelson AJ, Wilson TD. 2012. Computer visualizations: Factors that influence spatial anatomy comprehension. Anat Sci Educ 5:98-108.

Parsons LM. 1987. Imagined spatial transformation of one's body. J Exp Psychol Gen 116:172-191.

Parsons LM. 1994. Temporal and kinematic properties of motor behavior reflected in mentally simulated action. J Exp Psychol Hum Percept Perform 20:709-730.

Peters M, Laeng B, Latham K, Jackson M, Zaiyouna R, Richardson C. 1995 A redrawn Vandenberg and Kuse mental rotations test: Different versions and factors that affect performance. Brain Cognit 28:39-58.

Peterson DC, Mlynarczyk GS. 2016. Analysis of traditional versus three-dimensional augmented curriculum on anatomical learning outcome measures. Anat Sci Educ 9:529-536.

Petersson H, Sinkvist D, Wang C, Smedby O. 2009. Web-based interactive 3D visualization as a tool for improved anatomy learning. Anat Sci Educ 2:61-68.

Petit LS, Pegna AJ, Mayer E, Hauert CA. 2003. Representation of anatomical constraints in motor imagery: Mental rotation of a body segment. Brain Cognit 51:95-101.

Rehman FU, Khan SN, Yunus SM. 2012. Students, perception of computer assisted teaching and learning of anatomy - In a scenario where cadavers are lacking. Biomed Res 23:215-218.

Roach VA, Fraser GM, Kryklywy JH, Mitchell DG, Wilson TD. 2018. Guiding low spatial ability individuals through visual cueing: The dual importance of where and when to look. Anat Sci Educ (in press; doi: https://doi.org/10.1002/ ase.1783).

Shahab, N, Perveen K, HussainM. 2016. Sticking to traditions: Anatomy education and research in Pakistan. Anat Sci Educ 9:101-102.

SharpBrains. 2010. Brain teaser: Test your mental rotation skills. SharpBrains, San Francisco, CA. URL: https://sharpbrains.com/blog/2010/09/28/test-yourmental-rotation-skills/ [accessed 30 April 2018].
Shepard RN, Metzler J. 1971. Mental rotation of three-dimensional objects. Science 171:701-703.

Sims VK, Mayer RE. 2002. Domain specificity of spatial expertise: The case of video game players. Appl Cognit Psychol 16:97-115.

Sternberg RJ. 2015. Multiple intelligences in the new age of thinking. In: Goldstein S, Princiotta D, Naglieri JA (Editors). Handbook of Intelligence: Evolutionary Theory, Historical Perspective, and Current Concepts. 1st Ed. New York, NY: Springer Science+Business Media. p 229-241.

Sweeney K, Hayes JA, Chiavaroli N. 2014. Does spatial ability help the learning of anatomy in a biomedical science course? Anat Sci Educ 7:289-294.

Tarr MJ, Pinker S. 1989. Mental rotation and orientation-dependence in shape recognition. Cognit Psychol 21:233-282.

Tetris. 2018. About Tetris ${ }^{\circledR}$. Tetris Holding, LLC., Honolulu, HI. URL: https:// tetris.com/play-tetris/ [accessed 30 April 2018].

Tomasino B, Gremese M. 2016. Effects of stimulus type and strategy on mental rotation network: An activation likelihood estimation meta-analysis. Front Hum Neurosci 9:693.

Tosto MG, Hanscombe KB, Haworth CM, Davis OS, Petrill SA, Dale PS, Malykh S, Plomin R, Kovas Y. 2014. Why do spatial abilities predict mathematical performance? Dev Sci 17:462-470.

Trelease RB. 2016. From chalkboard, slides, and paper to e-learning: How computing technologies have transformed anatomical sciences education Anat. Sci Educ 9:583-602.

Uttal DH, Meadow NG, Tipton E, Hand LL, Alden AR, Warren C, Newcombe NS. 2013. The malleability of spatial skills: A meta-analysis of training studies. Psychol Bull 139:352-402.

Vandenberg SG, Kuse AR. 1978. Mental rotations, a group test of three-dimensional spatial visualization. Percept Mot Skills 47:599-604.

Visible Body. 2018. Human Anatomy Atlas: A comprehensive 3D atlas of the human body. Argosy Publishing Inc., Newton, MA. URL: https://www.visiblebody.com/anatomy-and-physiology-apps/human-anatomy-atlas [accessed 30 April 2018].

Vuchkova J, Maybury TS, Farah CS. 2011. Testing the educational potential of 3D visualization software in oral radiographic interpretation. J Dent Educ 75:1417-1425.

Wilson AB, Brown KM, Misch J, Miller CH, Klein BA, Taylor MA, Goodwin M, Boyle EK, Hoppe C, Lazarus MD. 2018. Breaking with tradition: A scoping meta-analysis analyzing the effects of student-centered learning and computer-aided instruction on student performance in anatomy. Anat Sci Educ (in press; doi https://doi.org/10.1002/ase.1789). 